\title{
A String of Pearls: Lessons for Medical Writing and Submitting for Publication
}

\author{
Christy J.W. Ledford, PhD
}

PRiMER. 2020;4:1.

Published: 1/13/2020 | DOI: 10.22454/PRiMER.2020.574980

In family medicine, we talk about clinical pearls-clinically-relevant lessons we learn through experience or observation. Clinical pearls are small bits of information that are freestanding and self-contained. ${ }^{1}$ That concept also translates to medical writing and publishing. The primary objective of publishing research is to share your findings with the scientific community-your peers. ${ }^{2}$ Sharing your work, whether it was a successful patient intervention or you disproved a clinical hypothesis, is an important step in building the evidence base. Through publication, you help your peers see what has already been discovered or tried; it enables them to take the next step or to know what not to do in their own work. The submission and review process also enables continuous improvement of research quality as you receive critical feedback from your peers.

In 2016, Dr Alan Blum, professor and the Gerald Leon Wallace, MD, Endowed Chair in Family Medicine at the University of Alabama, set out to collect pearls about writing and submitting articles to medical journals from the editors in our discipline. As a former editor himself (Medical Journal of Australia and New York State Journal of Medicine), he recognized a growing need for mentoring junior faculty, fellows, and residents in this essential but daunting part of academic life. Blum interviewed four editors of journals in family medicine to reach beyond the standard instructions to authors ${ }^{3}$ and discover what elements of the hidden curriculum ${ }^{4}$ exist in medical writing and editing.

\section{The Editors}

Teachers of family medicine look to peer-reviewed journals to learn about advances in the field and to share their own discoveries of how to improve our discipline. Each of these journals is led by an editor who plays multiple roles in the review and publishing process.

The editors interviewed for this project included:

Marjorie A. Bowman, MD, MPA

Editor, Journal of the American Board of Family Medicine, 2003-present

Christopher P. Morley, PhD

Editor in Chief, Peer-reviewed Reports in Medical Education Research (PRiMER), 2017-present

John Saultz, MD

Editor in Chief, Family Medicine, 2010-present

Kurt Stange, MD, PhD

Editor, Annals of Family Medicine, 2002-2019

The editor plays three roles through the review process: gatekeeper, curator, and shepherd. As gatekeeper, an editor controls what appears in print by selecting which manuscripts are forwarded for peer review. ${ }^{5}$ The role of gatekeeper is important for quality control. Editors protect reviewer time by only advancing complete, audience- 
appropriate papers through the review process. Editors also play the role of a curator, who carefully selects and organizes the intellectual ideas of a discipline. In describing a journal's purpose, Saultz said, "a medical journal done properly is the diary of an intellectual or scholarly community." Through guiding and directing authors in how to improve their work, editors also play the role of a shepherd. It is in this spirit that the following five pearls, distilled from the editor interviews, provide lessons for authors as they seek to share their work.

\section{Pearl 1: Read the Literature}

The first step in researching or practicing evidence-based medicine is reading the literature. ${ }^{6}$ Bowman reported that "[the American Board of Family Medicine] encourages the people who are doing board certification to read journals and to participate in research." Reading spurs your own creative thought and ability to write research questions. Spending time in the literature also immerses you in the structure and function of medical writing. ${ }^{7}$

When you read current literature, you not only learn what investigators are contributing to the evidence base, you also see where gaps remain and what additional question needs to be asked. Saultz said, "My number one frustration is how badly read the field is. The main reason we reject papers is inadequate literature." Your manuscript demonstrates how well you have read the literature. Include references that (1) provide background and support the rationale for the study in the introduction, and (2) situate your findings in a larger context in the discussion. Saultz is not alone; research shows that reviewers rank incomplete, inaccurate, or outdated review of the literature as one of the top 10 reasons a manuscript is rejected. ${ }^{8}$ Maggio and colleagues provide concrete advice on writing a literature review throughout the research process. ${ }^{9}$

\section{Pearl 2: Work With a Team}

The practice and teaching of family medicine relies on a team of clinical and educational professionals working together. ${ }^{10}$ Writing for family medicine is no different. Research and writing is a complex undertaking that requires a variety of experiences and skills. ${ }^{11}$ Bowman commented on the team nature of publications, "We have had lots of papers that are interdisciplinary, with authors who are anthropologists, sociologists, or mental health professionals." Morley encouraged:

"This isn't something you have to do on your own, nor should it be something you have to do on your own. Work in teams, find the collaboration you need, find the skill sets you need to build a team, and find the mentorship you need, because it is worth it and can build a whole new aspect to your professional life."

Writing in teams provides key opportunities for mentorship. ${ }^{12}$ As faculty members develop and mature, they should move into mentor roles in writing teams. Saultz urged:

You should stop writing papers on your own and start writing papers with young people... what I want to see is the number of single-author publications by assistant professors, and especially single-author publications by full and associate professors, to stop because if you are involving the young people in the department in your work, then everything gets leveraged and they learn habits from you that they can then teach to other people downstream.

\section{Pearl 3: Target Journals When Submitting Papers}

In any communication, a prime directive is: target your audience. ${ }^{13,14}$ When researchers are ready to share their findings, they need to ask who needs this new information. ${ }^{15}$ Each medical journal has aims and a scope-these help define the journal's audience. After you write the first draft of your manuscript, visit the website of potential target journals, and consider how well your manuscript aligns with each journal's stated aims and scope. Stange summarized:

"I think there is a lot of overlap in all the journals, and all of them want to have the article that the clinician can use for the next patient they see in family practice... Family Medicine certainly is the place that publishes educational research, so we [Annals] tend to not do that. We don't do case reports, but the Journal of the American Board of 
Family Medicine does."

As the newest journal in family medicine, PRIMER provides an outlet for junior authors to share short articles about small studies. Morley elaborated, "The real focus is on original research about medical education specific to primary care. We want to make it an educational journal. We also want student and resident authors."

In describing the complementary nature of the journals of family medicine, Saultz distinguished them by audience and purpose:

"For us [Family Medicine], the community that most of our papers is trying to communicate with is people who teach family medicine or one of the other primary care disciplines for a living. That is our core group. The readership of [JABFM] is the diplomates of the Board... Annals should be the cutting-edge research journal in primary care perhaps for the world and certainly for the western hemisphere."

Bowman echoed that description, "We are geared to what works for the clinical family physician and concurrently improve research in the field."

\section{Pearl 4: Learn From the Reviews You Receive, Make the Paper Better, and Try Again}

After you submit a manuscript to a journal, if the editor decides the paper is a good fit for the journal, the editor sends it out for peer review. A scientific peer review is not like a grade-it's not about passing or failing. Peer review is about finding out from your target audience what's missing in your paper and how it can be better. One question they address is novelty. Saultz pointed out, "The peer review process is about your colleagues in your field who have expertise in that field determining whether your ideas are new and valid."

Sometimes reviewers identify methodologic flaws that can only be fixed by collecting new data or running another analysis. But an editor's decision to "revise and resubmit" provides feedback on how to better tell your story. ${ }^{16}$ Editors use decision letters to help you. As Stange explained, "I try to frame things in terms of not as much criticism as why we didn't accept it but as suggestions as to what they might do if they want to do something to improve it before they send it to another journal."

Editors pay attention to who authors are and how they can help develop their skills. Bowman shared her approach:

"When we get papers from residents or medical students with a faculty member coauthor, I either write a review myself or get the paper reviewed even if we are pretty certain that it won't hit the mark to get published. This is so that they get feedback on their papers. This is our mentorship."

\section{Pearl 5: Be a Reviewer}

When you review an article, you look for how the manuscript describes what we already know and how this manuscript will contribute to and extend that knowledge. ${ }^{17}$ Too frequently in our own writing, we make mental assumptions that prevent us from seeing what's missing in our work. The more you perform reviews for manuscripts, the more easily you can look at your own writing through a reviewer's lens. You begin to anticipate what a reviewer might ask and include that information before you submit.

The peer review process relies on a community of peers. ${ }^{18}$ This group of editors recognized that our discipline needs more experienced reviewers. Bowman said, "Trying to find people who know the subject area well enough on all the topics that we receive is not easy." And it is not just about subject matter expertise. When those who receive their own reviews are writing reviews for others, a virtuous cycle is created, in which reviewers and authors edify each other to build a strong evidence base. Saultz observed, "There isn't a sense of community if there is not peer review."

\section{Acknowledgments}

Melani Harrell, Department of Family, Internal, and Rural Medicine of the University of Alabama School of Medicine, 
Tuscaloosa, gave her time to transcribe the interviews.

Disclaimer: The views expressed within this publication represent those of the authors and do not reflect the official position of Uniformed Services University of the Health Sciences, the US Government, or the Department of Defense at large.

\section{Corresponding Author}

Christy J.W. Ledford, PhD

Uniformed Services University of the Health Sciences, Department of Family Medicine, 4301 Jones Bridge Road, A1040U, Bethesda, MD 20814. 301-295-0703. Fax: 301-295-3100.

christian.ledford@usuhs.edu

\section{Author Affiliations}

Christy J.W. Ledford, PhD - Department of Family Medicine, F. Edward Hébert School of Medicine, Uniformed Services University of the Health Sciences, Bethesda, MD

\section{References}

1. Lorin MI, Palazzi DL, Turner TL, Ward MA. What is a clinical pearl and what is its role in medical education? Med Teach. 2008;30(9-10):870-874. https://doi.org/10.1080/01421590802144286

2. Knottnerus JA, Tugwell P. Communicating research to the peers. J Clin Epidemiol. 2007;60(7):645-647. https://doi.org/10.1016/j.jclinepi.2007.01.003

3. Orkin AM, Phillips WR, Stange KC. Research Reporting Guidelines and the New Annals Instructions for Authors. Ann Fam Med. 2016;14(6):500-501. https://doi.org/10.1370/afm.2008

4. Hafferty FW. Beyond curriculum reform: confronting medicine's hidden curriculum. Acad Med. 1998;73(4):403-407. https://doi.org/10.1097/00001888-199804000-00013

5. Crane D. The gatekeepers of science: some factors affecting the selection of articles for scientific journals. Am Sociol. 1967;2(4):195-201.

6. Guyatt G, Rennie D, Meade M, Cook D. Users' Guides to the Medical Literature: A Manual for Evidence-based Clinical Practice. 3rd ed. New York: McGraw-Hill Education; 2015.

7. Greenhalgh T. How to read a paper. Getting your bearings (deciding what the paper is about). BMJ. 1997;315(7102):243-246. https://doi.org/10.1136/bmj.315.7102.243

8. Bordage G. Reasons reviewers reject and accept manuscripts: the strengths and weaknesses in medical education reports. Acad Med. 2001;76(9):889-896. https://doi.org/10.1097/00001888-200109000-00010

9. Maggio LA, Sewell JL, Artino AR Jr. The Literature Review: A Foundation for High-Quality Medical Education Research. J Grad Med Educ. 2016;8(3):297-303. https://doi.org/10.4300/JGME-D-16-00175.1

10. Roth LM, Markova T, Monsur JC, Severson RK. Effects of implementation of a team model on physician and staff perceptions of a clinic's organizational and learning environments. Fam Med. 2009;41(6):434-439.

11. Ledford CJ, Seehusen DA, Villagran MM, Cafferty LA, Childress MA. Resident scholarship expectations and experiences: sources of uncertainty as barriers to success. J Grad Med Educ. 2013;5(4):564-569. https://doi.org/10.4300/JGME-D-12-00280.1

12. Shah J, Shah A, Pietrobon R. Scientific writing of novice researchers: what difficulties and encouragements do they encounter? Acad Med. 2009;84(4):511-516. https://doi.org/10.1097/ACM.0b013e31819a8c3c

13. Parrott R. Emphasizing "communication" in health communication. J Commun. 2004;54(4):751-787. https://doi.org/10.1111/j.1460-2466.2004.tb02653.x

14. Schrager S. Transforming your presentation into a publication. Fam Med. 2010;42(4):268-272.

15. Cals JW, Kotz D. Effective writing and publishing scientific papers, part X: choice of journal. J Clin Epidemiol. 2014;67(1):3. https://doi.org/10.1016/j.jclinepi.2013.09.014

16. Kotz D, Cals JWL. Effective writing and publishing scientific papers, part XII: responding to reviewers. J Clin Epidemiol. 2014;67(3):243-243. https://doi.org/10.1016/j.jclinepi.2013.10.003

17. Spigt M, Arts ICW. How to review a manuscript. J Clin Epidemiol. 2010;63(12):1385-1390. https://doi.org 
/10.1016/j.jclinepi.2010.09.001

18. Stange KC, Gotler RS. Tips for readers, reviewers, and authors advancing health and primary health care. Ann Fam Med. 2014;12(4):299-301. https://doi.org/10.1370/afm.1675

Copyright $@ 2020$ by the Society of Teachers of Family Medicine 